\title{
CRUZAMENTOS REPRESENTADOS
}

\section{IMAGOLOGIA E FIGURAÇÕES \\ DA ALTERIDADE}

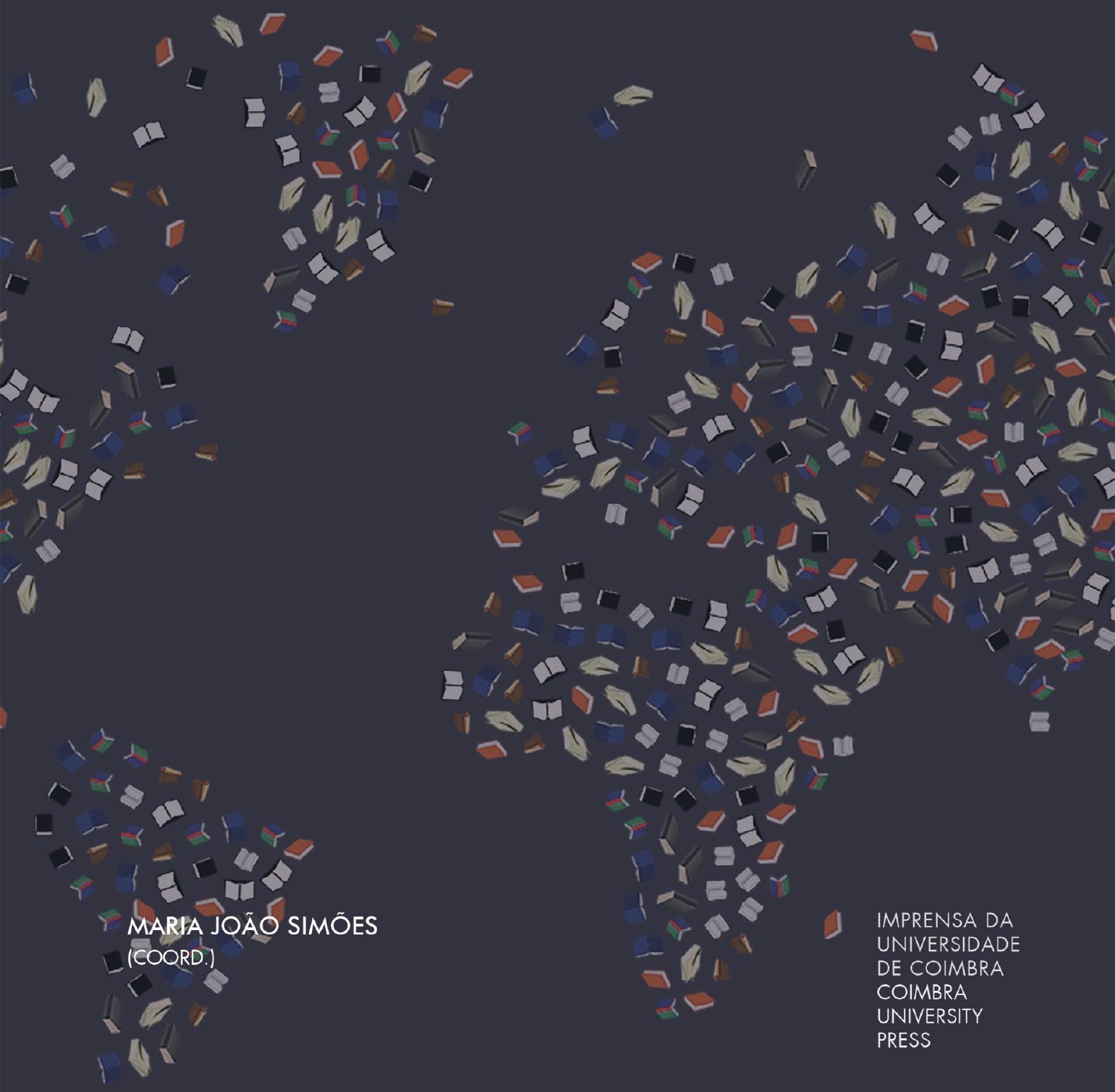


EDIÇÃO

Imprensa da Universidade de Coimbra Email: imprensa@uc.pt

URL: http//www.uc.pt/imprensa_uc

Vendas online: http://livrariadaimprensa.uc.pt

COORDENAÇÃO EDITORIAL

Imprensa da Universidade de Coimbra

CONCEÇÃo GRÁFICA

Imprensa da Universidade de Coimbra

IMAGEM DA CAPA

Imagem de Gordon Johnson por Pixabay

INFOGRAFIA

Raquel Aido

REVISÃo

Eduardo Nunes

ISBN

978-989-26-1941-5

ISBN DIGITAL

978-989-26-1942-2

DOI

https://doi.org/10.14195/978-989-26-1942-2 


\section{CRUZAMENTOS REPRESENTADOS \\ IMAGOLOGIA E FIGURAÇÕES \\ DA ALTERIDADE}

MARIA JOÃO SIMÕES

(COORD.)
IMPRENSA DA

UNIVERSIDADE

DE COIMBRA

COIMBRA

UNIVERSITY

PRESS 


\section{Í N D I C E}

INTRODUÇÃO

Da imagologia ao transnacionalismo literário . . . . . . . . . . . . 7 MARIA JOÃO SIMÕES

CAPÍTULO 1 - REPRESENTAÇÃO DE MINORIAS: A FICÇÃO INDIANO-AMERICANA

Indian Diasporic Fiction: The Role of the Model Minority

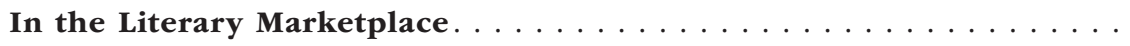

DOROTHY FIGUEIRA

CAPÍTULO 2 - REPRESENTAR O EMIGRANTE E O OLHAR MIGRANTE

Entre a identidade e a alteridade. Imagens de cidades brasileiras em Miguel Torga e Vitorino Nemésio . . . . . . . . . . . . . . . . . DORA GAGO

Fernando Assis Pacheco y Camilo José Cela. Personajes literarios

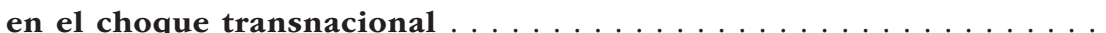
ALEXIA DOTRAS BRAVO

CAPÍTULO 3 - OLHARES DIFERENTES: EXÍlIO E RETORNO

Falar de um eu que já foi. Identidade, temporalidade e espacialidade em Biografia de Cristal de Jorge Listopad . . . . . . . . . . . . . . . . ISABELLE SIMÕES MARQUES 
Jogos de alteridade em contos de José Cardoso Pires . . . . . . . . . . . . 97 LOLA GERALDES XAVIER

CAPÍTULO 4 - OLHARES CRUZADOS ENTRE IDENTIDADE(S)

E ALTERIDADE(S)

Figuras imagológicas. Vivência e nostalgia da revolução 117 ANA MARIA MACHADO

Imagologia e Transnacionalismo. Figurações relacionais em John Berger, A. Tabucchi e J. Rentes de Carvalho. 141 MARIA JOÃO SIMÕES

CAPÍTULO 5 - TRANSCULTURALIDADE E OUTRIDADE:

DUAS CONCEÇÕES TEÓRICAS

Identidades híbridas: interculturalidade ou transculturalidade?

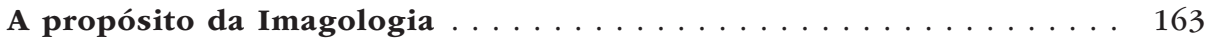
MARIA DE FÁTIMA GIL

Estrangeiros, espaços e identidades. Uma leitura de Estrangeiros a nós-mesmos de Julia Kristeva . . . . . . . . . . . . . . . . . . . . . . . . . . . . 179 JOÃO DOMINGUES 
MARIA JOÃO SIMÕES

Centro de Literatura Portuguesa - Universidade de Coimbra

http://orcid.org/0000-0001-6648-9097

I N T R O D U Ç Ã O

\section{DA IMAGOLOGIA AO TRANSNACIONALISMO LITERÁRIO}

\section{N T R O D U C T I O N \\ FROM IMAGOLOGY TO LITERARY TRANSNATIONALISM}

Este volume de ensaios congrega a investigação realizada no âmbito no projeto "Literatura, Imagologia e Transnacionalismo", desenvolvido no contexto das atividades do Centro de Literatura Portuguesa (CLP). Reúnem-se neste livro as reflexões apresentadas em workshops e em sessões de debate consagrados ao estudo não só das representações da identidade e da alteridade, mas também da representação intercultural e transnacional na literatura. Este trabalho investigativo insere-se no domínio da Imagologia, enquanto domínio da Literatura Comparada, que tem como objetivo estudar a construção das imagens nacionais em contraponto com imagens do Outro, considerado estrangeiro, mas, para além disso, o volume abre-se ainda ao campo do transnacionalismo literário, para abarcar representações de hibridismo identitário, característico de situações interculturais ou transnacionais.

À investigação que agora se apresenta preside o intuito de realizar análises críticas e desmontagens de preconceitos e estereótipos nocivos ao diálogo intercultural, partindo do pressuposto de que as obras literárias, com a sua reconhecida riqueza e complexidade gnoseológica, oferecem uma via de esclarecimento sobre os processos de representação de Si e do Outro. Subjacente a esta ideia encontra-se também a comprovação ${ }^{1}$ de

\footnotetext{
1 Já desde 2010, os relatórios de apreciação dos resultados dos ACT - testes de entrada no ensino universitário nos Estados Unidos -, permitiram concluir que os alunos mais
} 
que o texto complexo é fundamental para alcançar graus mais elevados de compreensão leitora, sendo reconhecido que as ficções literárias, ao acionarem o pluricódigo literário, manifestam uma grande complexidade compositiva, semântica e ideológica, pelo que se deduz ser da máxima importância promover a capacidade de ler textos literários complexos.

Para o estudo destas representações culturais incrustadas nos universos ficcionais é fundamental a componente personagem. Com efeito, no âmago dos códigos literários, a personagem literária é um elemento essencial para a construção das intrigas e das situações representadas na ficção e, na sua configuração, ela vai desenhando representações individuais que muitas vezes funcionam, metonimicamente, como representações coletivas e nacionais e do estrangeiro, sejam elas autoimagotipos ou heteroimagotipos. Assim, a identidade da personagem é tecida pela sua inserção na narrativa e no espaço-tempo representados (o cronótopo, segundo Bakhtine), mostrando-se nas suas atitudes e nos seus discursos, que expressam valores e ideias. Participa neste processo de inserção espácio-temporal da personagem, o conjunto de relações entretecidas com outras personagens, estabelecendo um jogo acionado por confronto e dissenso ou por concordância e aproximação. Ora, é dentro deste quadro relacional, claramente intersubjetivo e situado no espaço e no tempo, que se processa a passagem (ou o deslizar) da identidade coletiva à identidade individual, conforme esclarece Kenneth Meadwell:

Au cours du déroulement du récit, l'effet de réel qui véhicule l'identité d'un personnage peut se fonder justement sur les conséquences de son adhésion à un groupe ethnique ou religieux, ou à celui défini par d'autres critères, tout en mettant en relief son individualité. L'intérêt de ce glissement identitaire éventuel réside dans la spécificité des opérations narratives et discursives qui sous-tendent et définissent sur le plan spatiotemporel, et dans ses relations personnelles, la figuration du personnage. (Meadwell, 2012: 16).

preparados para entrar no ensino superior eram os que conseguiam ler textos complexos (cf. ACT, Inc. , 2006). 
A partir da teorização de Paul Ricœur, nomeadamente da distinção entre $i d e m$ e $i p s e^{2}$, Kenneth Meadwell retoma a diferença entre identidade-mesma e identidade de si-próprio (l'identité-mêmeté e l'identité-ipséité), e, com base nesta díade, explica a diferença entre um "eu" que permanece, que não se altera (semelhante, embora a outro nível, à representação estereotipada coletiva), e, por outro lado, um "eu” mutável, permeável às nuances e alterações do sujeito, ele-próprio ${ }^{3}$. Este raciocínio leva-o a um entendimento deste "eu" transformativo como um "alter". Se este desdobramento do sujeito direciona o olhar para uma alteridade psicológica, este processo não realiza sem a participação do diálogo com outros sujeitos, na medida em que qualquer sujeito está imerso na (e dependente da) convivialidade social. Em grande parte, a alteridade imiscui-se, infiltra-se e gera-se no próprio sujeito porque ele se pode ver como Outro que é diferente, sendo, portanto, a radicalidade do Outro, enquanto sujeito diferente, ou seja, na sua Outridade indispensável ao diálogo do sujeito consigo próprio. Esta é, afinal, uma das razões (e não é despicienda) que nos mostra quão relevante é conhecer aprofundadamente as relações do sujeito com o outro.

Para se captar melhor a abrangência do conceito de alteridade, será importante reter a ideia de que ser trata de um construto psicológico, o qual, como expõe Clive Hazell, pode ser abordado sob vários ângulos e domínios: Psicologia, Filosofia, Religião, Sociologia, Arte, etc.. Para este pensador, "different notions of alterity occur in different registers and on a developmental continuum" (Hazzel, 2009: XIV). Se os filósofos chamam a atenção para o modo como a radicalidade do Outro é fundamental para o entendimento do Si - como é o caso de Levinas -, ou apontam o papel da linguagem e da desconstrução do discurso para a apreensão do Outro - como poderá ser o caso de Derrida -, já os sociólogos e os pensadores

\footnotetext{
${ }^{2}$ Esta distinção é apresentada na obra Soi-même comme un autre, onde P. Ricœur reflete sobre a relação entre a identidade narrativa e a identidade pessoal (cf. Ricœur, 2012: 137) e sobre a dialética entre o "si-próprio" e "eu-mesmo" (idem, 168).

3 Meadwell distingue entre "l'identité-mêmeté ou l'identité que l'on peut réduire à la classification - celle d'une seule et même collectivité et de ses membres constituants - et l'identité-ipséité ou l'identité du soi, de l'individu unique” (Meadweel, 2012: 17).
} 
das ciências sociais apontam o papel fundamental dos contactos sociais para a formação do conceito de alteridade, enquanto construto social.

Flagrantemente, as ficções captam a variedade destes possíveis registros da alteridade, através dos processos miméticos utilizados na construção dos universos ficcionais, tornando-se visíveis na configuração das personagens e dos seus enquadramentos histórico-sociais.

Desvendar os meandros, os processos e as estratégias compositivas ficcionais é uma das incumbências da crítica literária e, neste âmbito, à Imagologia compete o estudo das múltiplas configurações das personagens e dos seus conflitos, na medida em que concorrem para esboçar representações coletivas nacionais e estrangeiras, pois toda e qualquer personagem se encontra imersa em contextos sociais específicos.

Este é o escopo restrito que Joep Leerssen propõe para a Imagologia enquanto campo de estudos da literatura comparada, quando afirma:

It is possible and necessary to distinguish between texts thematizing cultural differences and texts explaining those differences from imputed or perceived national characters in what is technically termed an ethnotype. Imagology does not adress the semiotics of cultural difference, but focuses on deconstructing ethnotypes and their characterological rationalization of cultural difference. (van Doorslaer, Flynn \& Leerssen, 2015: 3).

Ao dizer-se que este é um sentido restrito, não se pretende depreciar ou diminuir o papel da Imagologia, pois se reconhece o contributo inovador que esta perspetiva de análise tem trazido ao domínio da literatura comparada e, mais alargadamente, ao campo da crítica literária.

Contudo, se se acatar este sentido restritivo de J. Leerssen, muitos outros tipos de relações culturais ficam por analisar, nomeadamente as relações grupais mais circunscritas (que muitas vezes concorrem para as representações nacionais) e também os fenómenos de aculturação (forçada ou mais pacífica) e de hibridismo cultural.

É aqui que a resposta do transnacionalismo literário ganha relevo e importância, uma vez que descreve aspetos presentes em textos literários que desafiam a redução a referências ao nível estrito do Estado- 
-Nação. Com efeito, para Peter Morgan, o transnacionalismo literário "identifies that point at which two or more geo-cultural imaginaries intersect, connect, engage with, disrupt or conflict with each other in literary form”. (Morgan, 2017: 14). Como adverte Paul Jay (2010: 5, 73), a viragem transnacional na crítica literária não vem rasurar a perspectiva da crítica nacional, mas, ao assumir que toda a perspectiva crítica é uma construção a partir de um lugar (idem, 73), o transnacionalismo literário abre-se a uma investigação não só dos fenómenos e situações transnacionais, mas também dos processos e agenciamentos aplicados na representação artística.

Por todas estas razões, para além do estudo das literaturas nacionais, torna-se premente investigar a grande variedade de espaços de contacto cultural que, conforme sustenta Paul Jay, carece de novas perspectivas, deslocando-se, assim, o estudo para

a new, more contemporary engagement with transnational spaces, hybrid identities, and subjectivities grounded in differences related to race, class, gender, and sexual orientation, and the study of how culture and its practices are shaped and reshaped in border zones and liminal spaces that transgress the clear lines between states and the more fuzzy ones between nations (Jay, 2010: 16).

Numa sociedade globalizada como a do mundo contemporâneo - seja essa globalização político-economicamente imposta, forçada e desigual ou fruto de cruzamentos culturais mais benignos -, novas e diferentes interseções culturais vão emergindo, não deixando as obras literárias de repercutir e representar essas diferenças. Não está em jogo, aqui, uma perspectiva sociológica da literatura; trata-se, isso sim, de escrutinar como essas novas perspectivas teórico-críticas interpretam e analisam as misturas e os choques culturais resultantes dos intensos movimentos e fluxos sociais da atualidade, tal como esclarece Paul Jay:

Indeed, it is the intersection of these demographic changes with theoretical innovations in our understanding of the key role difference makes in the 
production and regulation of meaning that set the stage for the transnationalizing of literary studies. In this regard the social and political movements I mentioned (...) turned out to be crucial (Jay, 2010: 19).

A viragem transnacional advogada por Paul Jay apoia-se explicitamente num conjunto de pensadores que se debruçaram sobre problemas interculturais, como Arjun Appadurai, Homi Bhabha, Kwame Appiah, Marie Louise Pratt (com o seu conhecido conceito de "zona de contacto"), mas também Nestor G. Canclini, Edouard Glissant e Paul Gilroy.

Um dos conceitos mais importantes no quadro das reflexões destes e de outros pensadores é o de hibridismo - um conceito relançado por Edward Said e retomado por N. G. Canclini e por H. Bhabha. Utilizado num sentido metafórico - uma vez que é um termo importado da biologia -, este conceito, como já em 2001 alertava Néstor García Canclini $^{4}$, não está isento de equívocos e apropriações indevidas; por outro lado, trata-se de uma utilização metafórica que, à semelhança de outros empréstimos, contribui para identificar e explicar alianças fecundas ${ }^{5}$. Tirando partido do seu conhecimento das teorias bakhtianas - nomeadamente da sua noção de hibridização das vozes enunciativas e narrativas -, este antropólogo e crítico das ciências sociais coloca em evidência "a produtividade e o poder inovador de muitas misturas interculturais" (Canclini, 2001: 16), que ele observa e estuda de forma a sustentar o conceito de hibridismo.

Em clave mais figurativa, Edouard Glissant aborda a embricação cultural na obra $A$ Poética da Relação, destacando o seu sentido relacional e

4 O texto aqui referido é a introdução escrita pelo próprio autor, em 2001, para a reedição da obra Culturas Híbridas, embora, como se sabe, a primeira edição do seu famoso livro seja de 1990.

5 A propósito da migração de conceitos, já em 2012, Mieke Bal afirmava que "if the use of concepts in the natural sciences differs from their use in the humanities, we can still learn something from their travels in and among the sciences (Bal, 2002: 29). A autora não deixa de alertar também para a possibilidade de ocorrerem desvios nessa importação de conceitos. Considerando os conceitos não de forma essencialista, mas como representações, Mieke Bal advoga a sua funcionalidade e a sua importância, na medida em que os "concepts are the tools of intersubjectivity: they facilitate discussion on the basis of a common language” (idem, 22). 
interativo. Com base nas distinções teóricas de Deleuze e Guattari, o poeta antilhano distingue a identidade radicular (presa à terra e ao território) da identidade rizomática, que é uma identidade da relação ${ }^{6}$, aquela que se abre e resulta do contacto com o Outro e da relação entre culturas.

Se o raciocínio de Glissant se desenvolve sobretudo em torno das potencialidades do relacional, ele não apaga a irredutibilidade do "eu", que não se verga ao conhecimento total, uma vez que reconhece a "opacidade"7 do indivíduo. Com efeito, na conceção glissantiana, o acionamento da relação não dilui a opacidade dos $\operatorname{sujeitos}^{8}$, porque a relação é entendida não como apropriação ou pertença, mas como coexistência e parceria (cf. Mbom, 2005: 249).

Numa escala de relacionamento comunitário e social, o transnacional não apaga a singularidade, ou antes, o processo de ressingularização, conforme propõe Guattari. Sobre esta questão se debruça Birgit Mara Kaiser na introdução da obra Singularity and Transnational Poetics, mostrando como diferentes teóricos, ao falarem de transnacionalismo, ou em literatura de migrações, ou em hibridismo, regressam a um "nacionalismo metodológico”, que assim continua a estruturar as perspetivações e as abordagens. Por este e outros motivos, segundo B. M Kaiser, faz sentido aprofundar o conceito de singularização, sendo um dos objetivos

${ }^{6}$ O crítico e poeta pergunta-se a si próprio e a nós mesmos "se nos dias de hoje não nos seriam ainda necessárias obras fundadoras que se baseassem numa (...) dialética do desvio: afirmando, por exemplo, o rigor político, mas também o rizoma da relação múltipla com o Outro, e fundando as razões de viver de qualquer comunidade numa forma moderna do sagrado, que seria, em suma, uma poética da Relação". (Glissant, 2011: 24).

7 Como esclarece Clément Mbom, para Glissant, "l'opacité est une notion épistémologique qui accorde à chacun le droit de garder son ombre épaisse, c'est-à-dire son épaisseur psycho-culturelle. L'opacité ainsi comprise reconnaît l'existence chez chaque individu de faits culturels incompréhensibles à d'autres individus qui ne participent pas de la même culture" (Mbom, 2005: 248).

${ }^{8}$ Segundo Camille Pech de Laclause, a teorização de E. Glissant escapa quer a um reducionismo cultural, quer à normalização globalizadora, dado que " la pensée archipélique est indissociable du lieu qui l'a vu naître et de l'acte qui la diffuse. (..) Elle s'épargne ainsi le risque d'une" divagation " (...), ou " déculturation " (...), qui caractérisent les tentations normatives et réductrices de la mondialisation. Elle opère un réseau d'actions relatives entre elles et formant une totalité résistante, tout en leur garantissant leur acuité réelle par leur lieu particulier" (Laclause, 2018: 5). Com efeito, para Glissant, a relação está implicada numa dinâmica de contactos: "la Relation détruite, à chaque instant et dans chaque circonstance, par cette particularité qui signifie nos opacités, par cette singularité, redevient relation vécue" (apud Pech de Laclause, 2018: 5). 
desta obra perguntar "se e como as leituras crítico-literárias de âmbito transnacional podem beneficiar conceptual e metodologicamente de um pensamento sobre a singularidade" (Kaiser, 2015: 2).

Esta resiliência da singularidade - ou, noutros termos, a sua opacidade, tal como é reconhecida nas reflexões glissantianas - deve servir-nos de alerta para o indevido apagamento da radicalidade das diferenças culturais em certas teorias multiculturalistas, as quais, embora hasteando a bandeira do hibridismo, tendem a ver e a ler o Outro privado da sua outridade. Como Dorothy Figueira chama a atenção, na obra Otherwise Occupied. Pedagogies of Alterity and the Brabminization of Theory, a reificação da noção de hibridismo em algumas teorias pós-coloniais conduz a uma substituição da voz do migrante, do ocupado e do marginalizado, e, desta forma, conduz, se não ao apagar, pelo menos, ao mitigar, do empenhamento social desencadeador de mudanças, uma vez que qualquer questão de "real powerlessness or marginalization - such as that of the efficacy of theory to effect change - disappears, to be replaced by a posture of powerlessness steeped in a discourse of hybridity, indeterminacy of the signifier and so on" (Figueira, 2008: 63).

Também Jean Bessière (2018: 43) observa como muitos dos críticos que afanosamente preferem a noção de hibridismo não atentam (nem pensam) no jogo dual (ou múltiplo) dos enquadramentos antropológicos caracterizadores do romance contemporâneo. A dualidade (ou a multiplicidade ${ }^{9}$ ) dos quadros antropológicos em que assenta a construção da ficção contemporânea gera o que este crítico denomina por antropoïesis da transindividualidade - bem diferente de uma antropoïesis da individualidade que teria caracterizado o romance em épocas anteriores.

\footnotetext{
${ }^{9}$ Embora apresente a ideia de dualidade antropológica, Jean Bessière almeja ultrapassar binarismos, conforme se pode ver quando afirma: "The fantastic and commonsense world alliance shows that literary transnationalism, as it is exemplified by [contemporary] novels (...), can break binaries - the some and the other, the local and the global, the national and the transnational -, avoids reifying hybridity and references to national identities, and refuses to make cosmopolitanism, globalization, etc., paradigms that are ready to be used." (Bessière, 2018: 48).
} 
Todavia, é importante reparar no seguinte aspeto: se falar sobre o transnacionalismo e pensar os seus problemas ou os seus desafios pode tornar-se demasiado abstrato, pelo contrário, a análise estética das obras de arte, e, especificamente, das obras literárias, permite perspetivar tensões concretas.

Vale então perguntar: como se figuram (ou transfiguram), ou seja, como se traduzem esteticamente essas representações identitárias e essas tensões ou interseções culturais, enquanto construtos mentais? Dentro da lógica da representação artística, esta transfiguração realiza-se através de vários processos miméticos e de diversos processos de expressão artística que partem de um determinado conhecimento do real, apreendido e interiorizado pelo artista, o qual é, depois, transformado em diferentes modos expressão artística. Neste sentido, as representações estéticas apropriam-se dos construtos sociais mais ou menos estereotipados e das construções psicossociais - também estudadas, por exemplo, no domínio da Psicologia Social - e transportam-nos para figuras e universos ficcionais.

Enquadrada na importante investigação da Psicologia Social, a reflexão sobre configurações da identidade levada a cabo por Richard K. Herrmann, Richard K. e Marilynn B. Brewer, no texto intitulado "Identities and Institutions: Becoming Europeanin the Eu", avança com uma proposta tipológica. Abordando as identidades múltiplas, os autores afirmam que "as identidades podem ser aninhadas, concebidas por círculos concêntricos, à maneira de Matryoshkas, as conhecidas bonecas russas" (Herrmann and Brewer, 2004: 8), ou seja, encaixadas umas nas outras. Com uma feição diferente, outras identidades revelam ser identidades de interseção ou transversais ("cross-cutting”). Nesta configuração alguns membros de um grupo identitário, mas não todos, são também membros de outro grupo, ou seja, a partilha de convicções não atinge a totalidade dos membros. Noutras situações, as identidades revelam-se como "separadas", distintas. Aqui, "os diferentes grupos a que uma pessoa pertence são distintos uns dos outros e essas pertenças não se sobrepõem" (ibidem).

Estas três configurações, como a designação indica, são figurações facilmente identificáveis - embora nem sempre consciencializadas como 
tal. Presumivelmente, porém, não bastarão para traduzir todas as situações (nem era essa a intenção dos seus autores). O desafio será, então, encontrar e definir outros tipos de figurações identitárias. E é aqui que ganha relevo a figuração das personagens.

Se o conceito de transnacionalismo - tal como este é definido por Thomas Faist ${ }^{10}$ - se "refere a processos que transcendem fronteiras", sem ficar refém de uma única e excludente referência identitária, então é possível encontrar estas características em diversas em personagens literárias.

Para além das já muito investigadas figuras de migrantes (na sua declinação em emigrantes e imigrantes), de exilados, de oprimidos, é possível pensar, ainda, outros desenhos de personagens, menos tipificadas. Poder-se-á pensar nas personagens de identidades transviadas ou perdidas, como as que surgem nos romances de Patrick Modiano, que tentam recuperar os traços do seu passado para recomporem o puzzle da sua própria identidade - elementos e características que encontramos também em algumas personagens de Antonio Tabucchi, nomeadamente em Nocturno Indiano. Noutros casos, delineiam-se personagens de identidades confusas, como acontece com algumas personagens de Salmon Rushdie, mas também na protagonista do romance Myra de Maria Velho da Costa - são personagens que, por vários motivos e circunstâncias, já não sabem a que se arrimar em termos de pertença identitária, manifestando a sua confusão em momentos de grande tensão dramática. É possível observar a representação de personagens de identidade aprisionada, ou retida, como acontece com a personagem Nazneen, no famoso romance Brick Lane, de Monica Ali, pois a personagem é apresentada como uma jovem mulher do Bangladesh que, ao casar, vem morar para Londres, onde vive quase sem contacto com o lado de fora da sua casa, com o exterior, porque não tem autorização para sair.

\footnotetext{
${ }^{10}$ Guiado pelo intuito de clarificar as diferenças entre os conceitos de diáspora e transnacionalismo, Thomas Faist afirma: "While the term 'diaspora' always refers to a community or group (...), concepts such as transnationalism - and transnational spaces, fields and formations - refer to processes that transcend international borders and therefore appear to describe more abstract phenomena in social science language. By transnational spaces we mean relatively stable, lasting and dense sets of ties reaching behind and across borders of sovereign states. (Faist, 2010: 13).
} 
Uma feição diferente é verificável, por exemplo, em certas personagens de Ondina Braga, como acontece com a protagonista de Nocturno em Macau, a professora portuguesa que se encanta com as culturas macaense e chinesa, cuja vontade de pertença oscila entre a cultura de origem e a cultura estrangeira que a atrai. Neste caso, e em outros similares, será pertinente falar de identidades oscilantes, observáveis em personagens que saltitam entre um grupo e outro, no que diz respeito à partilha de crenças e convicções, ora se identificando com um, ora com o outro grupo. Por seu turno, no caso de Olga Gonçalves - através do seu romance Eis uma história e de outros ligados ao tema da emigração - é possível detetar o desenho de personagens de identidades intersetadas ${ }^{11}$, pois as personagens foram atravessadas pela cultura do país para onde emigraram e, quando solicitados a compararem situações ou sob o impulso de contextos que funcionam como molas propulsoras de recordações, deslizam para um sentimento de pertença à sociedade que os acolheu, incorporando essa pertença na sua situação atual de emigrantes regressados. No romance de temática contemporânea, é ainda perceptível a figuração de identidades líquidas (se quisermos aproveitar a noção de liquidez da teorização de Zigmunt Bauman), nomeadamente na construção de narradores-personagens cosmopolitas, concebidos como cidadãos do mundo, visíveis, por exemplo, em certos narradores de Antonio Tabucchi.

$O$ reconhecimento da diversidade figurativa e da variedade de processos acionados para a alcançar concede uma grande pertinência aos trabalhos que tomem por incumbência investigar essas representações romanescas ou literárias.

Os vários artigos deste volume não só giram em torno destas questões, abordando diferentes autores de diferentes pontos de vista percetivos, como tentam dar conta das representações da alteridade face a representações da identidade, numa perspetiva transnacional. $O$ instigante texto de Dorothy Figueira leva-nos a refletir sobre novas e camufladas formas de mitigar ou obnubilar o confronto com o Outro e a sua cultura, formas essas que emergem sob a capa de um pretenso multiculturalismo,

11 Visíveis também no romance Apocalipse dos trabalhadores de valter hugo mãe. 
no mundo académico e cultural americano. Um conjunto de artigos visa analisar casos específicos de representações literárias. Vitorino Nemésio e Miguel Torga, por exemplo, são objeto de estudo no texto de Dora Gago, salientando esta investigadora o modo específico como cada um dos escritores expõe a sua visão de cidades brasileiras decorrente de visitas e estadas em diversas cidades, mas também fruto da experiência de emigração para o Brasil, no caso de Torga. O tema da emigração é ainda abordado por Lola Xavier, na sua análise de contos de José Cardoso Pires, assim como o tema dos "retornados" que levanta questões curiosas à Imagologia. Noutros textos, o foco analítico principal é o olhar estrangeiro sobre os portugueses e sobre Portugal, como acontece em alguns narradores e personagens de Antonio Tabucchi e Rentes de Carvalho, estudados por Maria João Simões, mas também nos casos abordados por Alexia Dotras Bravo, relativos ao romance Trabalhos e paixões de Benito Prada de Fernando Assis Pacheco e aos relatos de Camilo José Cela, os quais constroem imagens de Portugal ou de portugueses, num jogo de troca de olhares entre a Galiza e Portugal, revelador de uma perspetivação dinâmica do migrante galego em Portugal. A experiência do exílio é abordada por Isabelle Simões Marques através da escrita autobiográfica de Jorge Listopad. Indo mais além da escrita literária, Ana Maria Machado aborda a construção de auto e heteroimagotipos relativos à Revolução do 25 de abril de 1974, em textos diarísticos coevos de Miguel Torga e Vergílio Ferreira, ou no romance Os Memoráveis de Lídia Jorge, confrontando as representações deste último romance com a imagem que Sérgio Tréfaut constrói de Portugal no documentário "Outro país: memórias, sonhos, ilusões... Portugal 1974/1975”. Um outro conjunto de artigos, analisa posições teóricas e conceptuais, como é o caso do artigo de Fátima Gil que confronta o modo de conceber a transculturalidade proposto por Wolfgang Welsch com outras perspetivas e teorias que valorizam a interculturalidade. Por seu turno, João Domingues aborda a teorização de Julia Kristeva sobre o conceito do "estrangeiro" e revisita a evolução que, ao longo da História, vai sofrendo a ideia de estrangeiro.

Todos os trabalhos aqui apresentados foram enriquecidos com discussões internas do núcleo de pesquisa sobre Imagologia do Centro de 
Literatura Portuguesa (CLP) e eles mostram claramente como cada escritor é, à sua maneira, um "componedor", pois, à semelhança do minucioso trabalho tipográfico, o escritor seleciona e compõe a sua escrita. Esta metáfora do escritor-componedor, porém, vai mais além da seleção das palavras, na medida em que os escritores selecionam e compõem representações e imagens, mostrando, ao longo deste processo, a sua ideologia, a sua focagem específica, mas também olhares e perspetivas que lhe são coevas. Todos estes olhares e estas perspetivas, nos seus cruzamentos e interseções, são contributos preciosos para nos compreendermos a nós próprios, para entendermos a nossa cultura e para conseguirmos dialogar com os "estranhos que nos batam à porta"12 - assim saibamos nós dar-lhes respostas adequadas.

\section{Referências bibliográficas}

ACT, Inc. (2006) Reading Between the Lines: What the ACT Reveals About College Readiness in Reading. Acedido a 20/9/2013, em https://www.act.org/content/ $\mathrm{dam} / \mathrm{act} / \mathrm{unsecured/documents/reading \_ summary.pdf}$

BAL, Mieke (2002). Travelling Concepts in the Humanities. A Rough Guide, Toronto / Buffalo / London: University of Toronto Press.

BAUMAN, Zigmunt (2017). Extraños llamando a la puerta, Barcelona: Paidós.

BESSIÈRE, Jean (2018). "Transnationalism, Its Oxymora and Double Anthropology”. In Vandebosch, Dagmar and D'Haen, Theo (eds.) (2018). Literary Transnationalism(s), Boston: Brill / Rodopi, pp. 37-49.

CANCLINI, Néstor García (2001). Culturas Híbridas, Barcelona: Paidós.

FAIST, Thomas (2010). "Diaspora and transnationalism: What kind of dance partners?”. In Rainer Bauböck, Thomas Faist (2010). Diaspora and Transnationalism: Concepts, Theories and Methods, Amsterdam: Amsterdam University Press, pp. 9-34.

FIGUEIRA, Dorothy M. (2008). Otherwise Occupied. Pedagogies of Alterity and the Brabminization of Theory, Albany, NY, State University of New York Press.

12 Cf. Bauman, 2017: 15. 
GLISSANT, Édouard, (2011). Poética da relação. Porto: Sextante Editora.

HAZELL, Clive (2009). Alterity. The Experience of the Other. Bloomington: AuthorHouse.

HERRMANN, Richard K. and Brewer, Marilynn B. (2004) "Identities and Institutions: Becoming Europeanin the Eu", in Herrmann, Richard K.; Risse-Kappen, Thomas; Brewer, Marilynn B. (eds) (2004). Transnational Identities: Becoming European in UE (Paperback) Lanham, MD: Rowman \& Littlefield Publishers, pp. 1-24. KAISER, Birgit Mara (ed.) (2015). Singularity and Transnational Poetics. New York / London: Routledge, Taylor \& Francis Group.

мвом, Clément (2005). "Pensée Archipélique et identité créole, matrices du cheminement glissantien", in Chevrier, Jacques (dir.) (1999). Poétiques d'Édouard Glissant, Presses de l'Université de Paris-Sorbonne, p. 246-253 (247).

MEADWELL, Kenneth (2012). Narrativité et voix de l'altérité. Figurations et configurations de l'altérité dans le roman canadien d'expression française. Ottawa, Ontario : Les Éditions David.

MORGAN, Peter (2017) "Literary Transnationalism: A Europeanist's Perspective", in Journal of European Studies, 47 (2017), 3-20 (14).

PECH DE LAClAuSE, Camille (2018). "Note de synthèse sur la Poétique de la relation d'Edouard Glissant", pesquisa realiza no " Littérature nationale, littérature mondiale - échanges, transferts ", https://www.academia.edu/36811220/ Note_de_synthèse_sur_la_Poétique_de_la_relation_dEdouard_Glissant RICGEUR, Paul (1990). Soi-même comme un autre, Paris, Seuil.

VAN DOORSLAER, Luc, Peter Flynn and Joep Leerssen. (eds) (2015) Interconnecting Translation Studies and Imagology. Amsterdam/Philadelphia: John Benjamins Publishing. 